task. We had a few other cases of spinal injury, but it is unnecessary to mention any details concerning them.

The number of buttock-wounds which we had under treatment is sufficiently remarkable. They were of all shades of severity-some being slight flesh-wounds, caused by the grazing of a shell or piercing of a bullet, while in others the greater portion, or even the whole, of the glutei muscles had been carried away by the explosion of a shell, and the ilium or sacrum injured at the same time. We had in all about eighteen such cases; and if it be true, as is alleged, that the Maréchal de Mac Mahon was wounded in this region, it can be taken as no indication of want of bravery if a soldier should unfortunately be struck there.

CASE XXIV. - Claude Sannier, artilleryman, was struck by a piece of shell on September Ist. He was admitted to Asfeld twelve days afterwards. We then ascertained that almost the whole of the left ilium was exposed, as well as the upper part of the sacrum. The glutei muscles were, on the left side, completely stripped off the bone, and torn from their attachments throughout almost the entire length of the crest of the ilium. On the right side of the sacrum, the soft parts were also very much injured. The entire length of the wound was twelve inches, and it was six inches wide at its broadest part. In the bottom of it, a considerable portion of the sacrum was exposed, and almost the whole of the dorsum ilii, which was fissured in several directions. A portion of bone seven inches long and five inches wide was exposed, black and dead. The wound around looked healthy; the granulations were springing up at the edges. Some fragments of bone showed signs of beginning to loosen. The patient lay constantly upon his face. His bowels were regular; he passed urine readily; and his appetite was good. He suffered absolutely nothing. He was twenty-two years of age, and looked a placid, good-tempered fellow. Nothing was done, save dressing the wound carefully, until October 6th, when I extracted several inches square of the outer table of the iliac bone, which had be come loose. The whole length of the crest itself would exfoliate; but, although loosened, it was not yet ready to come away. I transferred this fellow, in the best possible condition, to the surgeons of the Dutch ambulance, on October 8th. From first to last, his wound seemed to give him very little annoyance. He never complained, and I never saw in his face an expression in the very smallest degree indicative of suffering.

CASE XXV. - Jean Cabirol, 22nd Regiment of the Line, was wounded and armitted to hospital the same day as Sannier; and the nature of his wound was very similar, though not quite so extensive. It involved, however, about half of the left buttock, the muscles being torn away, and the bone exposed and fractured, both the ilium and the sacrum. The right buttock was also extensively lacerated. But it did not look by any means so horrible a wound as the last. Until September $25^{\text {th }}$, Cabirol got on pretty well, when he had a rigor, followed by sweating. The left leg began to swell enormously, into a condition of hard œedema, probably from occlusion of the iliac vein; and he died on October Ist, with all the symptoms of pyæmia. A post mortem examination showed well marked hypostatic congestion all over the fron of the body. He also had been lying constantly upon his face, like the last man. The left profunda vein was found to be full of pus. There could be no mistake about it. The pus was seen flowing up wherever the part was compressed, after slitting up the femoral vein, which, as well as the iliac, contained a soft red clot. The liver contained numerous abscesses; and in the lungs was a number of large yellow softish masses, like tubercle, which must have been deposits of pus, not yet softened down into ordinary abscesses.

There were two cases in which these buttock-wounds proved fatal from secondary hæmorrhage; and it may here be observed that the secondary hæmorrhage so frequent in gun-shot wound is one of the most serious of complications; it indicates that the fluids of the organism are vitiated by some poison, pyæmic or other. The already weakened forces of the constitution are still further lowered by the losses of blood, difficult to check, and ever ready to return; and the result generally is, that the patient yields, whether the original injury be a very severe one or a comparatively slight one. The main vessel of the injured part may be ligatured; but too often this serves merely as a temporary check ; and, if the patient do not succumb previously to the disordered state of his blood, the bleeding will recur probably when the ligature falls. The great frequency of secondary hæmorrhage has for its chief causes the absence or faultiness of sanitary conditions, and the debility of the patients, induced by privation from nourishing food, and the exhaustion and exposure to which they have been subjected. The means calculated to remove or anticipate such evils will, if applied, be of more value than the ligature in coping with secondary bleeding after gun-shot injury.

About this date (Sept. I Ith) we had a visit from Captain Brackenbury, chief representative on the Continent of the English National
Society for Aid to Sick and Wounded in War. His appearance was most acceptable. Up to that time we had heard nothing from the outside world. We knew not if Paris were besieged or taken, or if a victorious Republic had routed the hitherto victorious German legions. Soon after his visit, we received stores of all kinds-blankets, bedding, food, and surgical assistance in the persons of members of the English Society. What we had been up till then relying upon were the stores which we had brought with "s from Paris, partly supplied there by the French Society, and in part too by the English. During all the time we were at Sedan, the French Military Intendance supplied us with rations and with wine, and with a staff of hospital servants. Dr. Sims has, in his Report, already awarded a just tribute of praise to the lady-nurses, who arrived also about this time. I cordially endorse what he has said. I only wish we had had them from the outset. In that case, lives which were sacrificed through want of adequate nursing, or rather through the absence of any proper nursing at all, might have been saved. I suppose that it was unavoidable, that much which might have been done was, through the force of circumstances, left undone; but it is not the less distressing to reflect upon afterwards.

To-day we tasted, for the first time since our arrival, a most welcome treat. Some cans of Irish preserved milk, which is most excellent, reached us. This pleasure was, however, more than counterbalanced by a discovery of which we learnt the same day. During the bombardmeut of September Ist, a couple of fugitive Zouaves made their way into an underground cistern of water which supplied the hospital, all other supply from the town having been cut off. They went in to escape one form of death, only to meet, poor fellows! with another. They were drowned; and their bodies were not discovered until, the water becoming low in the cistern, it was found necessary to descend into it to get the daily supplies for the house. I did not object to eating horseflesh, to which for a day or two we were reduced, although I confess I did not like it ; but, when we discovered the nature of the infusions with which we had been washing it down, I admit that I for one, and $I$ believe all the rest, felt very uncomfortable.

\section{A CASE OF RUPTURED UTERUS.}

\section{By John M. Bryan, Jun., L.R.C.P., Northampton.}

MRS. L., aged 42, a washerwoman, living a few miles out of town, was at the full calculated period of her eighth pregnancy. She had never aborted. She had had bad health, and suffered from abdominal pain during the latter part of her pregnancy. She had always had hard labours and large children. She had been ill-treated by lier husband (a labouring man), and even turned out of doors in the middle of the night during the week preceding her confinement. The midwife, an experienced person, who attended her during her labour, stated that labour-pains commenced on the morning of Saturday, August 27 th, previously to which flooding came on; and that on the following Tuesday morning, about nine o'clock, she first felt the child's head per vaginam. Mrs. L. lost a considerable quantity of blood; but, as labour progressed, the flow ceased. She complained of pain high up in the stomach during labour, and was sick two or three times. During the last two hours she had very violent pains. A still-born male child was born at 2 P.M.; the placenta was removed with ease about twenty minutes afterwards. There was no faintness during labour ; but she became very faint momentarily about a quarter of an hour after the placental birth, and then vomited once.

At 7 P.M. (Tuesday, 3oth August) I was called in. The patient was propped up in bed, pallid and very faint; respiration was quick; the voice weak and scarcely above a whisper. The extremities were cold, and the surface covered with a clammy sweat. The abdomen was large and very tender to the touch. The uterus was contracted; there had been no external hæmorrhage. The placenta was removed entire. I lowered her head, gave diluted brandy, and spoonfuls of milk and arrowroot, a full dose of opium, ordered beef-tea to be made at once, and applied a bandage lightly to the abdomen, bottles of hot water to the feet. The sickness returned, the vomited matter being sometimes of yellowish green colour. I remained with her till IO P.M., and gave an unfavourable opinion; in fact, I thought she would not live through the night.

August 3Ist, Io A.M. She lay on her back, and had not slept since delivery. The before-mentioned symptoms continued. The face was expressive of pain. The abdomen was more swollen, tympanitic, and tender. I drew off about three ounces of dark-coloured turbid urine, and determined to examine the interior of the uterus, which I had ab. stained from doing the night before, thinking any additional pain and faintness might hasten her end in her then extreme state. On intro- 
ducing my hand into the uterus, which was contracted and contained only one or two small clots, it was found to be ruptured at its anterior part, near the neck : the hand passed easily through the rent amongst the bowels. No hæmorrhage followed the examination. I ordered linseed-meal poultices to be applied to the abdomen, and the opium to be continued every few hours; ice, soda-water, brandy, etc. ; hydrocyanic acid, and sal volatile in spoonfuls of water, were also ordered. At 6 P.M., she had not slept, but seemed a little more cheerful : the other symptoms remained as before. Laudanum was added to the poultices.

September Ist, I0.30 A.M. The patient had not slept. She had passed a little urine in the bed. She was becoming weaker. There was much abdominal pain, with vomiting of a coffee-ground colour. The lochial discharge was very offensive. I ordered an injection of carbolic acid per vaginam.

September 2nd. She passed a night of agony, faintness, and restlessness, with suffocative feelings, and expired at 2 A.M., sensible to the last.

Post Mortem Examination made by A. G. Osborn, Esq., of Dover, September 2nd, 4.30 P.M., fourteen hours after death.-There was no appearance of external violence or of ecchymosis on the abdomen or pubes. The abdominal muscles on section had an unusually dull red hue. The peritoneum was injected and dark red, with some fibrine between the contiguous edges of the intestine. The uterus was of the size of a child's head-dark-red anteriorly, as though a dusky-coloured hæmatine had stained the tissue. The peritoneum at the fold between the bladder and uterus was torn transversely for six inches, and the uterine tissue torn transversely for five inches anteriorly at its neck ; its tissue was two inches thick, and in a semiputrid pulpy state, of a dark port wine colour. Through this rent the hand passed readily.

REMARKS. - Did the lining membrane of the uterus give way on the Friday when the flooding commenced? If so, is it not probable that the rent continued to enlarge during labour, but that the peritoneal coat did not give way till after the birth of the child and placenta? and does not the sudden faintness and pain at the chest mark the time? After such a lesion, is it not surprising that life should have lasted sixty hours? Was the tearing owing to fatty degeneration of the uterine tissue, or to mechanical violence either from without or from pressure of the child's head, or from the first and last causes acting together?

\section{ON THE REACTION OF POTASSIC IODIDE WITH THE OFFICINAL TRISNITRATE OF BISMUTH.}

By W. Bathurst Woodman, M.D., and C. Meymott Tidy, M.B.

AN out-patient attending at the London Hospital was taking the bismuth mixture of its Pharmacopœia, when it was thought advisable to add iodide of potassium to the previous prescription. When she came the following time, she appeared much alarmed at a red precipitate in the mixture, which she supposed to be "red leard" purposely put in by some neighbour, the sediment having been almost colourless when she reached home. As no mention is made in the ordinary text-books of materia medica of the decomposition which takes place, although it is doubtless well known to metallurgists, it occurred to us to examine the reaction a little more closely. The change takes place slowly, and appears to consist in the formation of an iodide of bismuth, potassic nitrate remaining in solution. This iodide of bismuth is a dark-red substance of cubic form, and seems to be a simple iodide, which is almost insoluble both in water and in excess of potassic iodide. Some of its properties are curious. It is a very insoluble substance; for, in addition to what is mentioned above, we may add that saturated solutions of chloride of ammonium, chloride of sodium, ferrocyanide of potassium, and corrosive sublimate, do not dissolve it in any appreciable proportions. Acetic acid dissolves it slightly, without effervescence. On boiling with liquor potasse or ammonia, the hydrated oxide of bismuth $\left(\mathrm{H} \mathrm{Bi} \mathrm{O}^{4}\right)$ is produced, which is insoluble in excess of either reagent. On treating this iodide with strong nitric acid, there was active effervescence ; fumes of iodine being given off, a blackish, metallic-looking substance being left, entirely soluble in spirit, which proved to be pure iodine. Acid nitrate of bismuth remained in solution, which was not precipitated by a small quantity of water, or until neutralised. With hydrochloric or sulphuric acid there was no effervescence, but iodine was again precipitated; with the latter some iodic acid was formed. Oxalic acid also decomposed the salt, setting free the iodine; the action being somewhat slower than it was in the case of the mineral acids.

A few trials of it in doses of 5 to 20 grains appear to indicate that it is not an energetic therapeutic agent, which is probably to be ascribed to its comparative insolubility.

\section{REPORTS}

\section{or}

\section{MEDICAL AND SURGICAL PRACTICE IN} THE HOSPITALS OF GREAT BRITAIN.

\author{
ROYAL INFIRMARY, EDINBURGH. \\ CASE OF SKIN-GRAFTING. \\ (Under the care of Dr. Gillesyie.)
}

For the report of this case we are indebted to Mr. Page, M.B.

Two pieces of skin, each about a quarter of an inch in diameter, were removed from the front of the upper arm; the portions, being simply raised on a pair of dressing-forceps, and cut off with a stroke of the scissors, were placed upon the surface of an ulcer in a healthy granulating condition, but exhibiting tardy action. The pieces of skin were retained in position by strips of isinglass plaster, and the ulcer dressed in the usual manner with simple lotions, lint, and bandage.

Two days afterwards, the dressings were removed, and the patches were found adherent, with a very narrow bluish pellicle surrounding their margins. On the fourth day, an increase in the suppurative action was observed; and one of the patches fell off dead, while the other desquamated, leaving a delicate and transparent pellicle behind, resembling in every respect the film of cicatrix encroaching upon the breach of surface from the margins of the ulcer. On the sixth day, the patch had grown to nearly double its original size, and at one corner reached the circumference, with which, by the tenth day, a broad isthmus of communication was effected. When this occurred, the cicatrisation of the ulcer progressed rapidly, and by the twenty-third day it was complete.

At no period was there any temporary disappearance of the grafted skin; and the transparent and apparently vascular film, noticed first on the fourth day, continued to be visible and of similar appearance throughout.

I may state that the object in transplantation of skin in this instance was to heal a surface, the remains of a large callous ulcer, which, from the amount of cicatrisation that had already taken place, prevented further contraction of the surrounding textures.

\section{I D DLESEX HOS PITAL.}

PUERPERAL CONVULSIONS.

(Under the care of Dr. Hall Davis.)

THE patient in this case was a primipara. The attack followed delivery, and was preceded by cephalalgia. Anasarca, with albuminuria, was present. The attack came on during sultry, cloudy weather, accompanied by lightning and thunder.

Ellen A., married, aged 20, of good previous health, had lived in London for several years. She was plethoric, short-necked, and fullchested, and was delivered naturally of a fine living male child on August Ist, after twenty-four hours' labour. Three days before delivery, she complained of pains in the head, and had oedema of the lower extremities, eyelids, and hands. Labour went on favourably; but two hours afterwards she was seized suddenly with very violent epileptiform fits : the face became livid, the jaws firmly locked; the tongue was bitten; and foam issued from the mouth. There were clonic contractions of the muscles of the whole body. The fits recurred in quick succession until she was placed fully under the influence of chloroform. This was given for various periods on four occasions, between the hours of twelve and four. Each time, when its effects passed off, the fit became as violent as before. Ice was applied to the head; afterwards, blisters to the nape of the neck. A dose of ten grains of calomel and a minim of croton-oil was administered, but did not act for six hours. The fits continued severe; and the pulse, although in frequency only 84 , was very full, hard, and bounding. Thirty-four ounces of blood were taken from the arm. The pulse after this rose to 96 , and became soft and compressible. At 7.30 P.M., three hours after the venesection, she had no return of the fits. She was conscious, and complained of great headache and soreness of the tongue. The urine contained one-third albumen.

Aug. 2nd. The patient had had no return of the fits, and had slept fairly. She still complained of headache. She was thirsty. The skin was moist. Pulse 98, regular, full, but not very compressible. There was no tenderness over the abdomen. There was a fair amount of lochial discharge. There wàs a good secretion of milk. 